\title{
Biogeographical analysis of Finnish polypore assemblages
}

\author{
RAUNO VÄISÄNEN, KARI HELIÖVAARA, HEIKKI KOTIRANTA and TUOMO NIEMELÄ
}

\begin{abstract}
VÄISÄNEN, R., HELIÖVAARA, K., KOTIRANTA, H. \& NIEMELÄ, T. 1992: Biogeographical analysis of Finnish polypore assemblages. - Karstenia 32:17-28.

The analysis was based on the Finnish records in $100 \times 100 \mathrm{~km}$ quadrats of species of the polypore genera Phellinus, Coltricia, Inonotopsis, Inonotus, Onnia, Phaeolus, Fistulina, Polyporus, Ganoderma and Ischnoderma. Their distributions were preliminarily classified and related to environmental variables, using multivariate methods (two-way indicator species analysis, detrended correspondence analysis, canonical correspondence analysis). From the distribution patterns of the polypore species, it was possible to distinguish blocks of quadrats showing some resemblance to recognized vegetational zones. The continentality and number of tree species had the highest canonical coefficient values on the first axis of the canonical correspondence analysis, but the model was improved by the distribution of Picea abies and the proportion of grass-herb forest types. The quadrats with the most deviant rarity and typicalness indices were concentrated in the Aland archipelago, the surroundings of Helsinki and Turku, and in the area of the virgin forest of Pisavaara and the Päijänne lake district in southern Central Finland. These deviations reflect both exceptional species assemblages and uneven collecting activity.
\end{abstract}

Key words: biogeography, gradient analysis, polypores, rarity

Rauno Väisänen and Heikki Kotiranta, Water and Environment Research Institute (Nature Conservation), P.O. Box 250, SF-00101 Helsinki, Finland

Kari Heliövaara, Finnish Forest Research Institute, P.O. Box 18, SF-01301 Vantaa, Finland

Tuomo Niemelä, Department of Botany, Univer sity of Helsinki, Unioninkatu 44, SF-00170 Helsinki, Finland

\section{Introduction}

Polypores make up a morphological group of nongilled Basidiomycetes (Aphyllophorales), characterized by a poroid hymenophore and bracket-shaped or effused fruit body, which may be annual or perennial. More importantly, most polypores have a common ecology: they obtain their nutrients by decaying trees, living or dead. Only a very few species grow on humus or mineral soil, and even fewer are mycorrhizal. Polypores have been studied extensively, due to their economic significance, and at present they are the best-known group of fungi in Finland.

The distribution of polypores in Finland has been dealt with in several articles (Kotiranta \& Niemelä 1981, Niemelä 1985, Niemelä \& Saarenoksa 1989, Niemelä \& Kotiranta 1991). The present paper also includes unpublished data. The distribution of species has earlier been explained by factors such as the climate, zonation of the forest vegetation, distributions of the host trees, and the presence of certain environmental types, virgin forests in particular (e.g. Niemelä \& Kotiranta 1982, 1986, 1991), or the immigration history of the host trees (Erkkilä \& Niemelä 1986). However, no numerical biogeographical analyses have been presented.

In the present study, multivariate analysis techniques were applied to records of Finnish polypore genera that have recently been surveyed in Finland: Phellinus, Coltricia, Inonotopsis, Inonotus, Onnia, Phaeolus, Fistulina, Ganoderma, Ischnoderma and Polyporus. Multivariate analysis techniques such as detrended correspondence analysis (DCA) have been used to determine the dominant pattern in community composition variation through ordination of the species data (Hill \& Gauch 1980). Canonical correspon- 
dence analysis (CCA) has recently been developed to relate community composition directly to the known variation in the environment (Ter Braak 1985, 1986). Gradient analysis of this type can be applied to biogeographical data (Peet 1978, Luff et al. 1989, Eyre et al. 1990). These techniques have been tested on records of insects in other papers (Väisänen et al., in press, Heliövaara et al., 1991). The recently developed quantitative indices of rarity and typicalness (Eyre \& Rushton 1989) have also been applied here.

The study area was divided into subareas on the basis of polypore species assemblages. An attempt was made to identify biogeographical patterns by ordinating species and the quadrats in which they occur and by relating them to some environmental variables. The analyses revealed areas of special mycological importance characterized by rare and nontypical species.

\section{Material and methods}

The distribution maps of Finnish polypores were obtained from Niemelä \& Kotiranta $(1982,1983,1986$, 1991). These maps have been completed for this work. The herbaria of the universities of Helsinki, Turku, Oulu and Joensuu, the Forest Research Institute (Helsinki) and the Kuopio Museum of Natural History (Kuopio) provided the main material for the mapping. The authors T. Niemelä and $\mathrm{H}$. Kotiranta collected an extensive amount of supplementary data over the whole country. Voluntary cooperation of several biologists has greatly expanded the information on species distribution. Identifications of the material have been verified personally (by T.N. and H.K.) in every case.

The presence/absence data based on a $100 \times 100$ $\mathrm{km}$ grid system were used without taking species abundance into account. The grid cells are here called quadrats. Two quadrats with one species only were omitted from the analyses. The final number of quadrats was 55 and the number of species analysed 43 (Fig. 1). The number of species per quadrat varied from 3 to 35 and the mean number of species per quadrat was 17.8 (standard deviation 8.4).

Abbreviations consisting of the first four letters of the generic name and the first four of the species name, as used by Niemelä \& Kotiranta $(1982,1983$, 1986), are employed in the figures of the present paper. The names are given in full in Table 1. In two cases the abbreviations is formed differently, to avoid confusion with other species: Phellinus ferruginosus $=$ Phel ferr and Phellinus ferrugineofuscus $=$ Phel fefu, and Phellinus nigricans $=$ Phel nigr and Phellinus nigrolimitatus $=$ Phel nili .

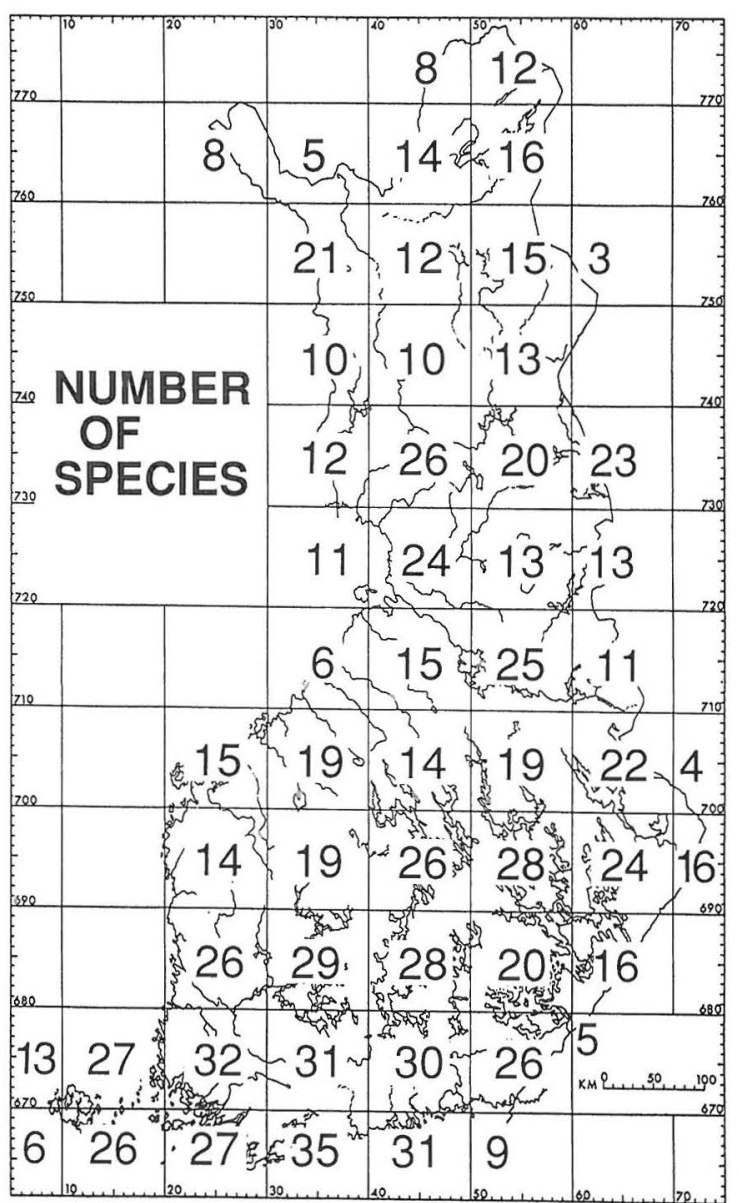

Fig. 1. Number of polypore species recorded in the quadrats according to the distribution maps in Niemelä \& Kotiranta $(1982,1983,1986,1991)$.

The major programs used in the analyses were TWINSPAN (Hill 1979a), DECORANA (Hill 1979b) and CANOCO (Ter Braak 1987). In the twoway indicator species analyses the number of indicators was 13 . Detrending by segments was used in the DCAs. In the weighted averaging methods (DCA, CCA), the eigenvalue is a measure of the separation of the species distributions along the ordination axis (Ter Braak 1986).

The following environmental variables were used in the CCAs:

- number of tree species (1-6) (TRE) (see Niemelä 1982);

- proportion of deciduous trees (DEC), using the scale $0,<10,20,30 \ldots 80 \%$ (Atlas of Finland 1976); 
Table 1. The percentage occurrence frequency of the polypore species in the eight groups interpreted from the TWINSPAN analysis. Species order is as given by the TWINSPAN. Values greater than 70 are in bold type. The number of quadrats in each group is shown in parentheses.

\section{Species}

Quadrat group

Species

100

Phellinus igniarius (L.) Quél.

Phellinus tremulae (Bond.) Bond. \& Borisov

Coltricia perennis (L.:Fr.) Murrill

Inonotus obliquus (Fr.) Pilát

Polyporus brumalis Fr.:Fr.

Polyporus ciliatus Fr.:Fr.

Phellinus chrysoloma (Fr.) Donk

Phellinus laevigatus (Karst.) Bourd. \& Galz.

Phellinus viticola (Schw. ex Fr.) Donk

Inonotopsis subiculosa (Peck) Parmasto

Polyporus pseudobetulinus (Pil.) Thorn, Kotiranta \& Niemelä

Phellinus nigricans (Fr.) Karst.

Phellinus pini (Brot.) A. Ames.

Phellinus conchatus (Pers.) Quél.

Phellinus lundellii Niemelä

Inonotus rheades (Pers.) Karst.

Ischnoderma benzoinum (Wahl.) Karst.

Polyporus tubaeformis Karst.

Polyporus leptocephalus Jacq.:Fr.

Phellinus ferrugineofuscus (Karst.) Bourd.

Phellinus nigrolimitatus (Rom.) Bourd. \& Galz.

Onnia leporina (Fr.) Jahn

Phellinus hippophaeicola Jahn

Coltricia cinnamomea (Jacq.:S.F. Gray) Murrill

Inonotus radiatus (Sow.:Fr.) Karst.

Ganoderma lipsiense (Batsch) Atk.

Polyporus melanopus Pers.:Fr.

Phellinus punctatus (Karst.) Pilát

Phellinus populicola Niemelä

Fistulina hepatica Schaeff.:Fr.

Phaeolus schweinitzii (Fr.) Pat.

Ganoderma lucidum (Curt.:Fr.) Karst.

Polyporus squamosus Huds.:Fr.

Phellinus ferruginosus (Scrad.) Pat.

Phellinus robustus (Karst.) Bourd. \& Galz.

Phellinus tuberculosus (Baumg.) Niemelä

Inonotus hispidus (Bull.:Fr.) Karst.

Inonotus dryophilus (Berk.) Murrill

Polyporus umbellatus Pers.:Fr.

Phellinus ribis (Schum.) Karst.

Onnia tomentosa (Fr.) Karst.

Onnia triquetra (Lenz) Imazeki

Polyporus badius (Pers.) Schw.

(10)

12

(18)

(7)

3

4
$(2)$

(3) $\begin{array}{rr}5 \\ (11)\end{array}$

$\begin{array}{rr}7 & 9 \\ (2) & (2)\end{array}$

$\begin{array}{rrrrrrrr}60 & 83 & 86 & 100 & 100 & 100 & 100 & 100\end{array}$

$\begin{array}{llllllll}80 & 89 & 71 & - & 100 & 100 & 100 & 100\end{array}$

$\begin{array}{llllllll}\mathbf{7 0} & \mathbf{7 8} & 57 & 50 & \mathbf{1 0 0} & \mathbf{1 0 0} & \mathbf{1 0 0} & 50\end{array}$

$\begin{array}{rrrrrrrr}90 & 61 & 71 & 50 & 100 & 100 & 100 & 100\end{array}$

$\begin{array}{rrrrrrrr}70 & 61 & 71 & 100 & 100 & 100 & 100 & 100\end{array}$

$\begin{array}{rrrrrrrr}20 & 94 & 57 & 50 & 67 & 91 & 100 & 100\end{array}$

$\begin{array}{llllllll}40 & 72 & 71 & - & 67 & 100 & 100 & 50\end{array}$

$\begin{array}{llllllll}20 & 83 & 43 & 50 & - & 100 & 50 & 100\end{array}$

$\begin{array}{llllllll}- & 5 & - & - & - & - & - & - \\ - & 5 & 14 & - & - & - & - & -\end{array}$

$\begin{array}{llllllll}50 & 55 & 43 & - & 33 & 100 & 50 & 50\end{array}$

$\begin{array}{rrrrrrrr}30 & \mathbf{7 8} & 57 & 50 & 67 & \mathbf{1 0 0} & \mathbf{1 0 0} & \mathbf{1 0 0}\end{array}$

$\begin{array}{llllllll}10 & 61 & 71 & 50 & 100 & 100 & 100 & 100\end{array}$

$\begin{array}{llllllll}30 & 78 & 43 & - & 100 & 100 & 100 & 50\end{array}$

$\begin{array}{llllllll}20 & 44 & 57 & - & 67 & 91 & 50 & 100\end{array}$

$\begin{array}{llllllll}30 & 72 & 43 & - & 67 & 100 & 100 & 100\end{array}$

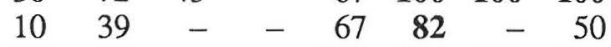

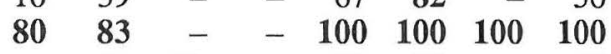

83
$-\quad 83$

-8314
$-\quad 8$

$\begin{array}{rrrrrrrr}- & 83 & 14 & - & - & 82 & - & 100 \\ 20 & 72 & 14 & - & 33 & 82 & - & -\end{array}$

$-5-100-950 \quad 50$
-500

- $-50-9-10$

$\begin{array}{llllllll}10 & 39 & 57 & - & 100 & 100 & 100 & 100\end{array}$

$\begin{array}{llllllll}10 & 28 & 86 & - & 100 & 100 & 100 & 100\end{array}$

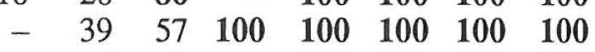

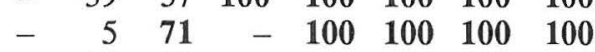

$\begin{array}{lllll}-\quad 22 & - & - & 91100100\end{array}$

- $-\quad-50-9100100$

$\begin{array}{llllllll}- & 17 & 14 & 50 & 100 & 100 & 100 & 100\end{array}$

$\begin{array}{rrrrrrrr}- & 17 & 14 & 50 & 100 & 100 & 100 & 100 \\ - & 11 & 14 & - & - & 82 & 100 & 100\end{array}$

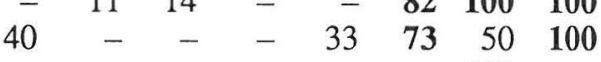

$-\quad-\quad-\quad-\quad-100-$

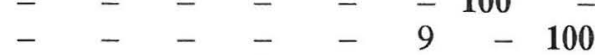

$-\quad-50 \quad-\quad 45100100$
-

- $\quad$ - $\quad$ - $\quad-\quad-50$

- $\quad$ - $\quad$ - $\quad$ - $\quad$ - $\quad-\quad-50$

- $\quad-\quad-\quad-\quad-\quad 36 \quad 50100$

- $\quad-\quad-\quad-679$ - 67

$\begin{array}{rrrrrrrr}- & - & - & - & - & 64 & 50 & - \\ - & - & - & - & - & 9 & - & - \\ - & - & - & - & - & 9 & - & -\end{array}$ 
- proportion of Pinus sylvestris (PIN), using the scale $0,<10,20,30 \ldots 80 \%$ (Atlas of Finland 1976);

- proportion of Picea abies (PIC), using the scale 0, $<10,20,30 \ldots 80 \%$ (Atlas of Finland 1976);

- proportion of grass-herb forest types (GRA), using the scale: $1=<1.1,2=1.1-5.0,3=$ $5.1-10.0,4=10.1-20.0,5=20.1-30.0$ and $6=$ $>30 \%$ (Atlas of Finland 1960);

- annual precipitation (PRE), using the scale: 1 $<400,2=400-450,3=451-500,4=501-550,6$ $=601-650,7=651-700$ and $8=701-750 \mathrm{~mm}$ (Atlas of Finland 1960);

- annual mean temperature (TEM), using the scale: $1=-2.0-1.0,2=-1.1-0.0,3=0.1-1.0,4=$ $1.1-2.0,5=2.1-3.0,6=3.1-4.0,7=4.1-5.0$ and $8=5.1-6.0^{\circ} \mathrm{C}$ (Atlas of Finland 1960);

- proportion of quartz (QUA), using the scale: $0=0$, $1=<10,2=11-20,3=21-30 \%$ (Atlas of Finland 1960);

- continentality index $(\mathrm{CON})$, using the scale: $1=$ $22-23,2=24-25,3=26-27,4=28-29,5=$ $30-31,6=32-33$ and $7=34-35$ (Tuhkanen 1980);

- humidity index (HUM), using the scale: $0=-10$, $1=0,2=10,3=20,4=30,5=40$ and $6=50$ (Thornthwaite's moisture index, Tuhkanen 1980).

Values for the variables related to the trees were determined according to their general distribution in a given quadrat, while the values of the other variables represent the mid-point ones. The arrow lengths in the CCA ordination diagrams indicate the importance of the environmental variables in question. The arrow roughly points in the direction of maximum variation in the corresponding variable.

The canonical coefficients in the CCA are the coefficients of a weighted multiple regression of the sample scores on the standardized environmental variables. Student's t-test is not appropriate for tests of significance of canonical coefficients. However, when the t-value of a variable is less than 2.1 in absolute terms, the variable does not add much to the contributions of the other variables in the analysis to the fit of the species data. In such a case there is no effect uniquely attributable to the specific variable and it can be deleted without any marked alteration in the canonical eigenvalues (Ter Braak 1987).

The inter-set correlations of the environmental variables with the CCA axes are the correlation coefficients between the environmental variables and the species axes consisting of the sample scores. They do not become unstable when the environmental variables are intercorrelated. The fraction of total vari- ance in the standardized environmental data that is extracted by each species axis is equal to the mean squared inter-set correlation. If the variance inflation factor (VIF) of a variable is large ( $>20)$, the variable is highly correlated with the other variables and therefore makes no unique contribution to the regression equation. As a consequence, its canonical coefficient is unstable and does not merit interpretation (Ter Braak 1986).

Rarity indices were calculated using a three-step procedure as described by Eyre \& Rushton (1989). Two scales of rarity based on the canonical (geometric) system were used. The indices were as follows:

- PRT (polypore rarity total): Species recorded in 1, $2-3,4-7,8-15,16-31$, and 32 or more quadrats were given scores of 6 to 1 , respectively. A site score was the sum of the scores for each species; - SRT (species rarity total): The scale was similar to that of PRT, except that the scores corresponding to the number of quadrats counted were the geometric values $32,16,8,4,2$ and 1 , instead of 6 to 1 . The index was the sum of these scores;

- RAT (rarity association total): This index was calculated in order to identify quadrats with several rare species. A value for a site was calculated using species that scored 2 or more on the geometric scale. The highest score was reduced to that of the nearest score, in order to eliminate bias caused by one very rare species in a list in which one score was far greater than the others. Thus, if a species list contained the scores $32,16,8,4,2,1$ and 1 , the 32 score would be reduced to 16 and all the scores of 2 or more would be summed. Finally, this score was added to the SRT to give the index;

- PQF (polypore quality factor) was obtained by dividing PRT by the number of species in the quadrat;

- SQF (species quality factor) was obtained by dividing SRT by the number of species in the quadrat;

- RQF (rarity quality factor) was obtained by dividing RAT by the number of species in the quadrat.

Typicalness indices were calculated using means and standard deviations of site ordination scores generated from an analysis of all the data (DCA) (cf. Eyre \& Rushton 1989). The coordinates of each quadrat calculated in standard deviations of the ordination score for DCA axes 1 (TYP1) and 2 (TYP2) were interpreted as typicalness measurements. High absolute values for the measurements indicate a deviant polypore flora. 


\section{Results}

\section{Species grouping and regional division}

The species were divided into 15 groups according to their distribution given by TWINSPAN (Fig. 2).

The primary division of the species may be associated with the host tree distribution. Species associated with deciduous trees with a southern distribution (Quercus, Fraxinus, Corylus, Castanea) were allocated to the lower main branch. Species purely associated with coniferous trees were mostly placed in the upper main branch. However, Onnia tomentosa, $O$. triquetra and Phaeolus schweinitzii were allocated to the lower main branch, although they are associated with widespread coniferous hosts. The main or sole hosts of Phellinus populicola and Ganoderma lipsiense are deciduous trees which are distributed over virtually the whole of the country, but the species were placed in the lower main branch, as were also two fungi which grow from buried wood or sclerotia, and whose host tree species is therefore unclear (Coltricia cinnamomea, Polyporus umbellatus). Hence, the primary division seems to separate polypores with southern or south-western distributions from those which occur evenly over the whole country, or are northern in their occurrences.

A map based on the TWINSPAN classification is shown in Fig. 3. The Åland archipelago formed a

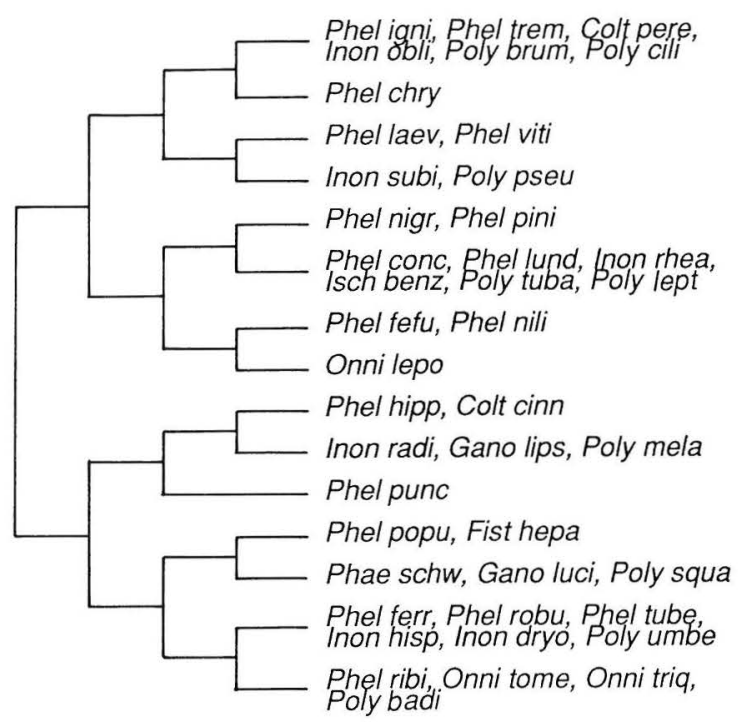

Fig. 2. A species dendrogram of a two-way indicator species analysis (TWINSPAN). group consisting of southern and northern sister groups. Several quadrats in southern Finland formed a group with sister groups in southeastern Finland and in the surroundings of the town Oulu. Western Aland formed a group with a highly scattered sister group occurring in eastern, central and northern Finland, all the quadrats being characterized by a small number of species. Northeastern Finland formed a separate group, but two quadrats in western Finland near the town of Vaasa also belonged to this group. Its sister group consisted of several species-poor quadrats along the Finnish border in the north and one quadrat in central Finland.

The frequency of occurrence of species in the quadrat groups interpreted from TWINSPAN is shown in Table 1. Eight species occurred in all eight

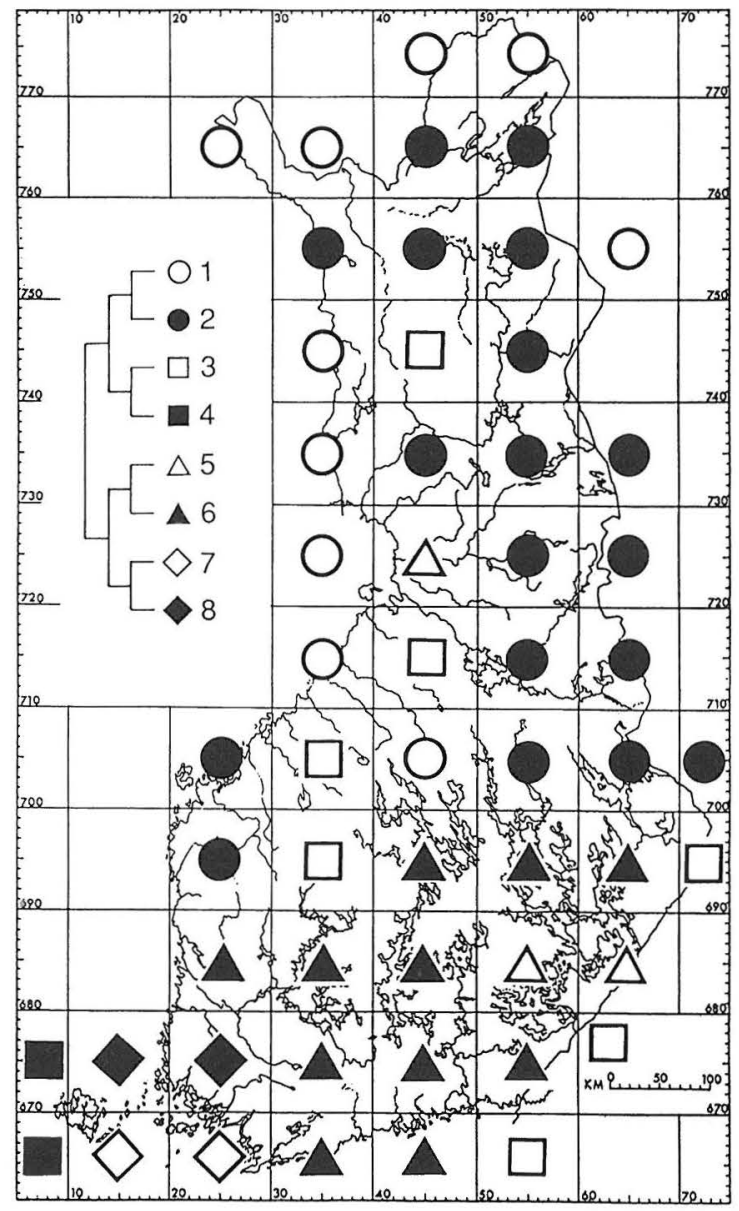

Fig. 3. Distribution of the quadrats in the groups interpreted from the TWINSPAN analysis in Finland. 
quadrat groups. Six species (Inonotopsis subiculosa, Phellinus ferruginosus, Inonotus hispidus, I. dryophilus, Onnia triquetra and Polyporus badius) were recorded in one group only. Groups 1-2 roughly represent the northern or northern-continental species composition, found in many polypores. Groups 3-4 may possibly simply reflect the least studied parts of the country, having an erratic, haphazard combination of species records. Groups 5-6 comprise species with a southern boreal distribution; the records of many vascular plants show that an 'island' of similar species composition really exists in the surroundings of Oulu. Groups 7-8 indicate the region in which a strong hemiboreal element is found.

The quadrat clusters ordinated by DCA (Fig. 4) corresponded well with those classified by TWINSPAN. However, the eigenvalues were low. The symbols of the southwestern groups 4, 7 and 8 lay on the right-hand side of the diagram, but the western Alandic quadrats were rather widely spaced. The open circles of group 1 covered a relatively large space in the ordination, but the triangles of groups 5 and 6 were densely packed in the middle of the figure. The black dots of group 2 formed a cluster on the upper part of the left-hand side.

Environmental variation and species assemblages

The polypore data showed relationship to variation in the environment. The CCA ordination diagram (Fig. 5) illustrates the polypore species assemblage in relation to a number of environmental variables. The canonical coefficients of the continentality (CON) and the number of tree species (TRE) received the highest absolute value on the first axis, but the distribution of Picea (PIC) and the proportion of grass-herb forest types (GRA) also contributed to the fit of the species data (Table 2). The generally low values of the VIFs indicate that the variables are not highly correlated with each other. The second axis was mainly related to the continentality. The fraction of total variance in the environmental data extracted by species axis 1 was $35.0 \%$, by axis $212.0 \%$, and by axis $30.05 \%$. The number of tree species together with the annual mean temperature, the proportion of

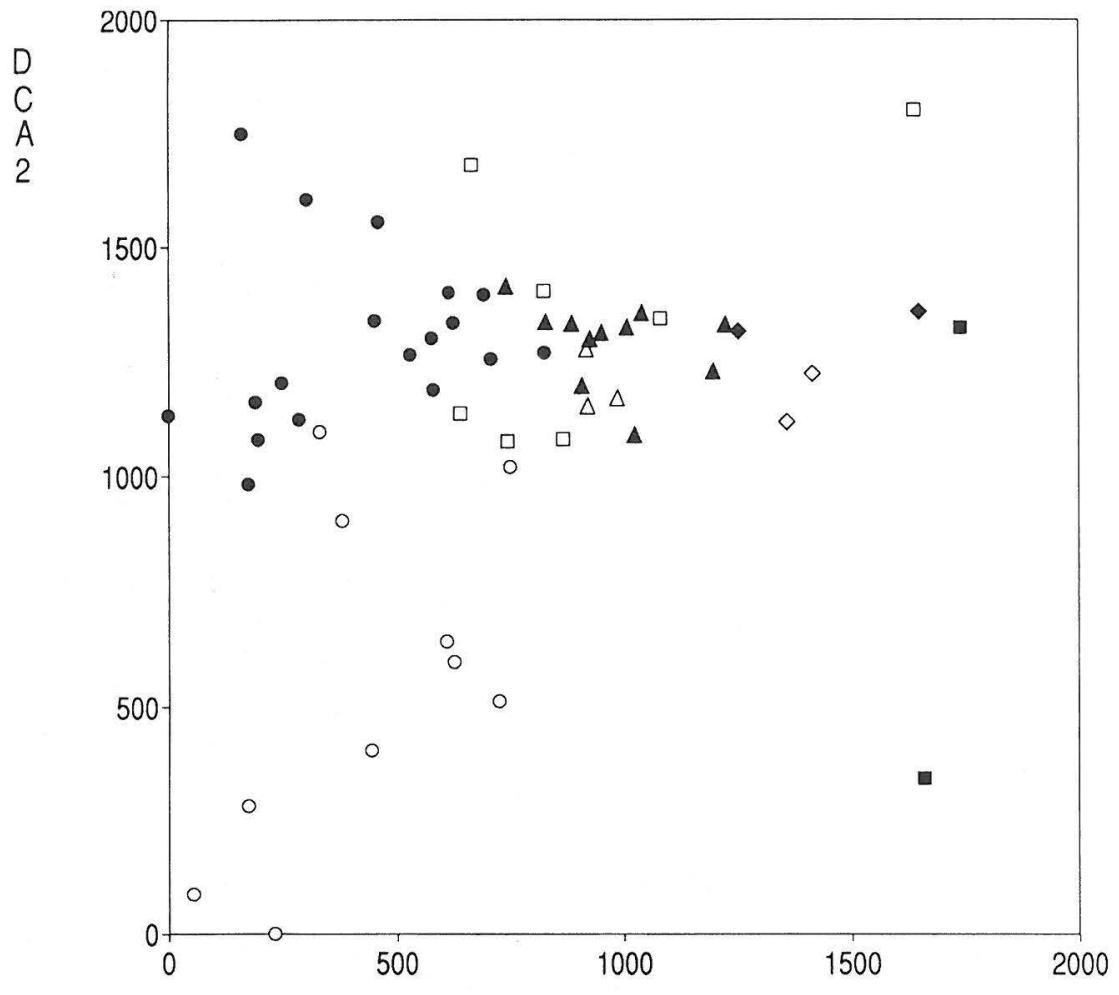

DCA 1 Fig. 4. The quadrats plotted on the 1st and 2 nd axes (eigenvalues 0.16 and 0.08 ) of detrended correspondence analysis (DCA) ordination. 


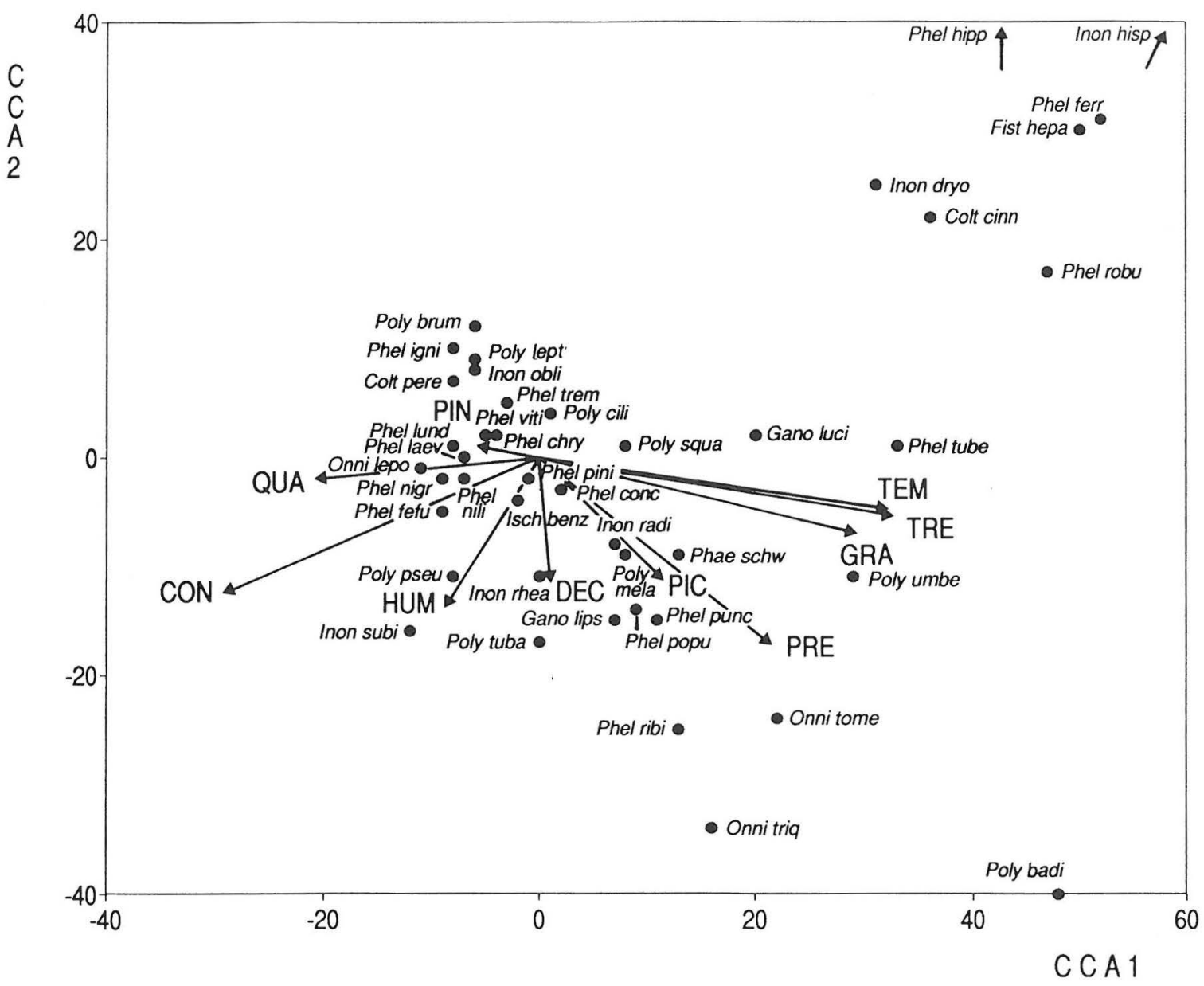

Fig. 5. Ordination diagram based on canonical correspondence analysis (CCA) of the distribution of polypores in the Finnish quadrats with respect to eight environmental variables (arrows). The species abbreviations consist of the first four letters of their generic and specific names (see Table 1 for full names). The environmental variables are: number of tree species (TRE), proportion of deciduous trees (DEC), proportion of Pinus sylvestris (PIN), proportion of Picea abies (PIC), proportion of grass-herb forest types (GRA), annual precipitation (PRE), annual mean temperature (TEM), proportion of quartz (QUA), continentality (CON) and humidity (HUM). The eigenvalue for axis 1 is 0.24 and for axis 20.07 .

grass-herb forest types and the continentality, seem chiefly to determine the species composition along axis 1 . This axis shows a fairly good positive (number of tree species, annual mean temperature, proportion of grass-herb forest types) or negative (continentality) correlation with these variables. Axis 2 was related to the annual precipitation, and to some extent to the proportion of deciduous trees, humidity and continentality, and to the distribution of Picea.
The polypore species in the upper right section of the diagram are those which have the clearest dependence on the hemiboreal climate. The evidence is indirect in this case, but the environmental variable associated with the number of tree species (TRE) is an indication of this. The species may share a sensitivity to extreme minimum temperatures, as seen from the variable continentality (CON). There may be some preference of limestone areas (cf. the proportion of 
Table 2. Canonical coefficients, variance inflation factors (VIFs) and the inter-set correlations of environmental variables with the first three axes of canonical correspondence analysis (CCA) in the polypore data. Canonical coefficients with an absolute $t$-value $>2.0$ are indicated by ${ }^{x}$. For the abbreviations of the environmental variables, see the legend of Fig. 5.

\begin{tabular}{lcccccrr}
\hline & \multicolumn{3}{c}{ Canonical coefficients } & \multicolumn{3}{c}{ Correlation coefficients } & VIFs \\
Axis & 1 & 2 & 3 & 1 & 2 & 3 & \\
Eigenvalue & 0.15 & 0.06 & 0.04 & & & & \\
\hline Variable & & & & & & & \\
TRE & $0.22^{\mathrm{x}}$ & -0.04 & 0.12 & 0.87 & -0.18 & -0.03 & 13.0 \\
DEC & 0.02 & 0.02 & -0.04 & 0.03 & -0.40 & 0.10 & 1.8 \\
PIN & 0.02 & -0.00 & $-0.17^{\mathrm{x}}$ & -0.15 & -0.04 & -0.34 & 1.8 \\
PIC & $-0.11^{\mathrm{x}}$ & 0.05 & $-0.25^{\mathrm{x}}$ & 0.30 & -0.38 & -0.40 & 3.7 \\
GRA & $0.16^{\mathrm{x}}$ & -0.05 & -0.04 & 0.78 & -0.24 & 0.06 & 4.0 \\
PRE & 0.08 & -0.13 & 0.07 & 0.57 & -0.60 & -0.09 & 8.5 \\
TEM & -0.07 & -0.11 & 0.10 & 0.85 & -0.18 & -0.03 & 18.3 \\
QUA & 0.04 & -0.05 & 0.08 & -0.56 & -0.07 & -0.17 & 3.7 \\
CON & $-0.23^{\mathrm{x}}$ & $-0.24^{\mathrm{x}}$ & $0.13^{\mathrm{x}}$ & -0.78 & -0.43 & 0.09 & 4.6 \\
HUM & 0.03 & -0.04 & -0.05 & -0.24 & -0.47 & -0.35 & 2.8 \\
\hline
\end{tabular}

grass-herb forest types, GRA), but it is not directly indicated.

The group of species in the lower right section of the diagram are southern, but lack a strong affinity to the western coastline, trees with a southern distribution, or an extremely oceanic climate.

The species aggregation in the centre cannot be easily subdivided. In that group, the species in the lower right half may be more demanding in their ecology than those situated in the upper left of the diagram. Many species in the centre and near the lower left are those called boreo-continental by Renvall et al. (1991). They are usually fairly tolerant or indifferent in their general ecology, but prefer a continental climate with cold winters, and live mostly in virgin forests.

\section{Rarity and typicalness}

The six rarity indices calculated for the polypore data are presented in Fig. 6. The polypore rarity totals (PRT) in the quadrats varied widely, from 6 to 106 , the highest value being obtained for the quadrat containing Helsinki. High values (83-93) were also obtained for some quadrats in southwestern Finland. The lowest values were obtained for two eastern quadrats on the Finnish border. This variation was strongly related to the number of species recorded in a quadrat, since the differences in the polypore quality factor $(\mathrm{PQF})$ were considerably smaller. The highest $\mathrm{PQF}$ values were obtained for two quadrats in the Åland archipelago and for that containing Helsinki.

Roughly the same quadrats received the highest values when a geometric scale was used, but the differences were amplified. The highest species rarity totals (SRT) were calculated for the quadrats lying in southwestern Finland, but high values were also obtained for the quadrat enclosing the middle parts of Lake Päijänne (158) and for that containing Pisavaara Strict Nature Reserve (162). As was the case with PRT, the SRTs were related to the number of species in the quadrat. The differences in the SQFs were higher than those for the PQFs but the use of the geometric scale caused relatively small changes in the ranking of the highest-quality quadrats. However, the quadrats of the Päijänne district, Oulu and Pisavaara were more clearly distinguished from the adjacent quadrats.

The rarity association totals (RAT) gave higher values than SRT, but the results are otherwise fairly similar. The highest RAT was obtained for Helsinki (452) and for two quadrats in the Alland archipelago $(366,374)$. As with the SRT, the RATs were related to the number of species in the quadrat (RQF). There was some re-ordering of the highest-quality quadrats 
compared to the RATs. Two quadrats in the Aland archipelago $(13.9,11.7)$ and Helsinki $(12.9)$ had the highest $\mathrm{RQF}$ values.

The typicalness measurements for the quadrats are presented in Fig. 6. The highest values of TYP1 were obtained for two quadrats in western Åland $(2.1,2.3)$ and for one quadrat in southeastern Finland (2.1). The quadrats with the highest absolute TYP2 values were mainly restricted to the northern parts of Finland and western Åland, indicating deviant species assemblages.

\section{Discussion}

The regional division suggested by the present results roughly agrees with the delimitation of the hemiboreal zone (groups 4, 7 and 8 in Fig. 3) and the southern boreal zone (groups 5 and 6) presented by Ahti et al. (1968). However, the middle boreal subzone could not be separated from the northern boreal one. The explanation may lie in the selection of polypore species for the study. Unfortunately, the species exhibiting the clearest boreo-continental distribution have so far remained unmapped. The picture would have been changed by inclusion of Trichaptum laricinum, Gloeophyllum protractum, Daedaleopsis septentrionalis, Tyromyces kmetii, Fomitopsis rosea and some more rare polypores with a northeastern distribution.

Several species were widely distributed, but our material included no widely distributed species characteristic of northern Finland only. However, our field observations indicate that species do exist which are widespread in the north and the interior of southern Finland, but which do not occupy the southern or western coastal belts. Amylosystis lapponica, Antrodia albobrunnea and Dichomitus squalens may belong to this group.

The most evenly distributed species in this analysis was Phellinus igniarius. The true situation may be more complex, because recent crossing studies (Fischer 1987) have revealed many sibling species in the complex, and they most probably have different requirements, host preferences and distributions. The new species would be very difficult to distinguish on the basis of dead herbarium material, and a collective concept has therefore been retained. The next species in the list (Table 1), Phellinus tremulae, Coltricia perennis, Inonotus obliquus and two species of Poly- porus are truly indifferent, occurring virtually everywhere in the country.

Phellinus chrysoloma has usually been considered boreo-continental in Finland. The scattered records from most parts of the country conceal this tendency, but the species is constant and abundant only in the north, and has economic significance only there.

The dual ecology and to some extent also the bipolar distribution of Polyporus leptocephalus ( $v a-$ rius) and $P$. squamosus (Niemelä \& Kotiranta 1991) can be seen, e.g. in Table 1. No crossing tests have been made with the ecotypes of these taxa, but our impression is that sibling species are not involved under these names.

The hemiboreal, southern element is visible throughout the results. Some of these polypores (Fistulina hepatica, Phellinus robustus) grow only on trees whose natural distribution is hemiboreal. Such fungi often fail to follow their hosts into parks or other plantations further north, or do so very seldom. This may indicate that the area inhabited by such fungi is in fact restricted by climatic factors. This is even clearer among species which have a hemiboreal distribution, but whose hosts are more widespread (e.g. Phellinus tuberculosus).

The present study included less than one quarter of the total polypores in Finland. This artificial group is ecologically similar to many wood-inhabiting hydnaceous fungi, Corticiaceae, stereoid fungi and also certain agarics. A biogeographical analysis of this group of decayers of tree trunks and solid woody debris can be expected to reveal clear differences from the other fungal groups of the forest ecosystem, viz. the humus-inhabiting and mycorrhizal fungi.

The rarity indices had high values in southwestern Finland and Alland, and in one area with virgin forests. In southwestern Finland, the high values were connected with the biotic richness of the hemiboreal subzone and with the cultivation of exotic tree species in parks around Helsinki (Erkkilä \& Niemelä 1986) and the town of Turku. The high values of SRT and RAT in the lake district are due to the greater collection intensity there than in the surrounding areas. The Pisavaara Strict Nature Reserve is one of the best investigated areas in Finland. The diversity of its biotopes and its luxuriant spruce-dominated virgin grass-herb forests have resulted in an exceptionally rich polypore flora. Such rarities as Inonotopsis subi-

Fig. 6. (Next opening). The rarity indices (PRT, PQF, SRT, SQF, RAT, RQF) of the polypores for each quadrat (for the calculation, see the text) and the typicalness measurements for the quadrats calculated for DCA axis 1 (TYP1) and for DCA axis 2 (TYP2). 

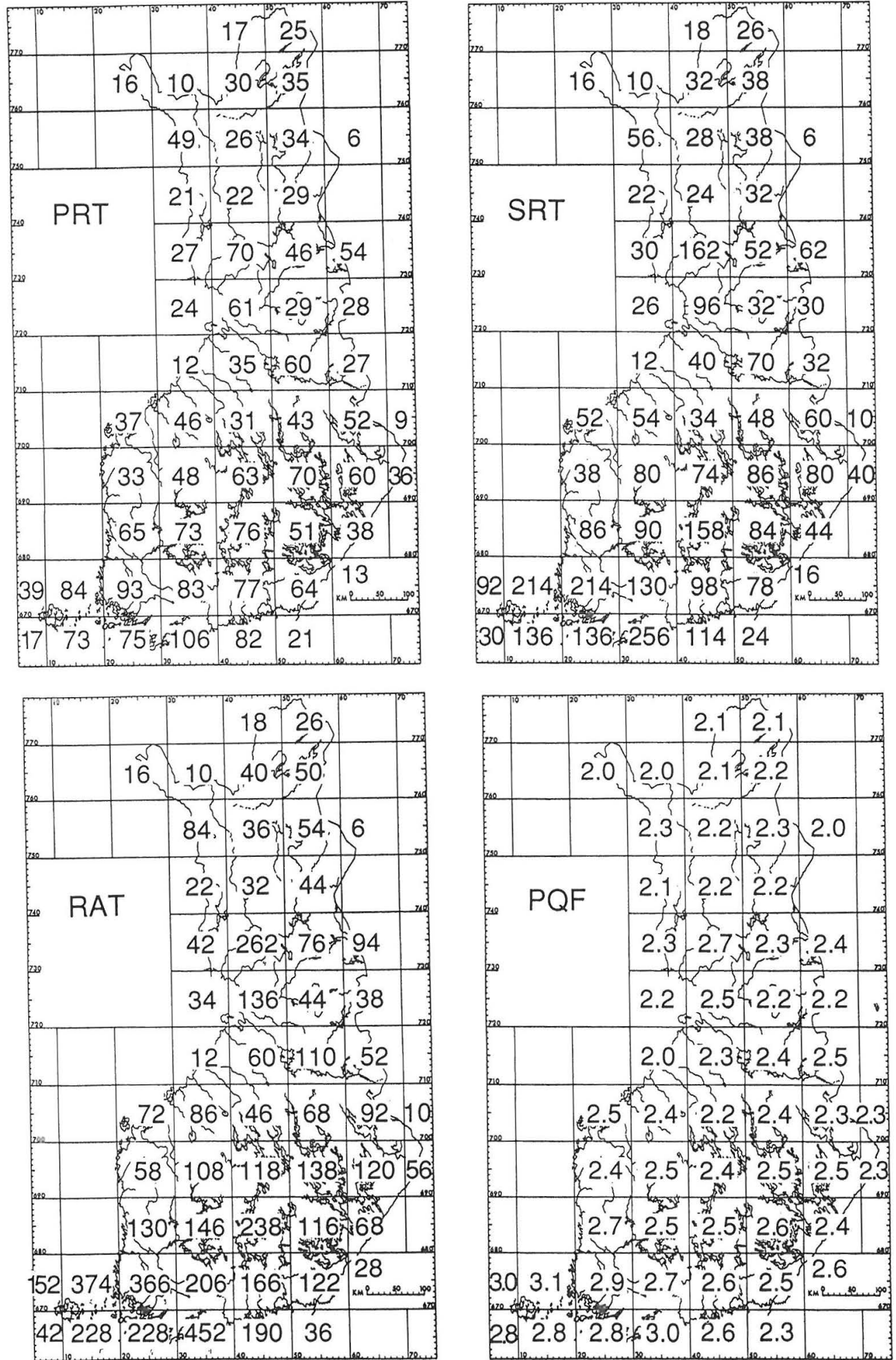

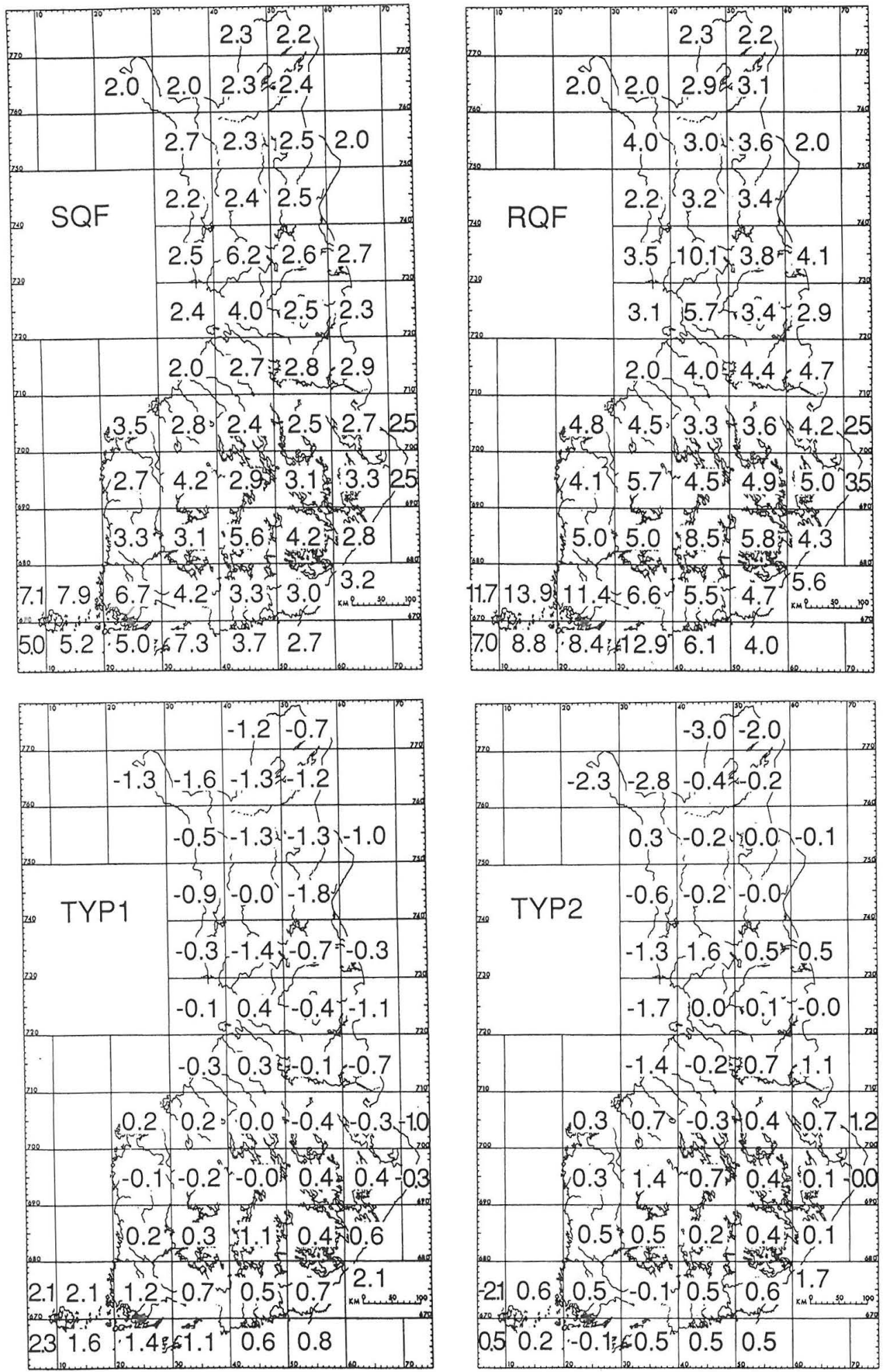
culosa and Polyporus pseudobetulinus are found there.

The present typicalness indices showed that the most deviant quadrats lie in the marginal areas of Finland. However, the quantification of typicalness has generally been considered difficult. Eyre \& Rushton (1989) tried two methods of calculating site typicalness using ordination scores derived from DCA. They considered it more appropriate to use ordination scores derived from analyses of individual habitat group data, rather than those derived from analyses of the total data. In the present case, the number of quadrats per group was not high enough to allow this approach.

Multivariate techniques provide effective tools for numerical biogeographical analyses. The present results suffer, however, from the scarcity of data and the large quadrat size. Consequently, definite biogeographical conclusions may be premature, but the results can be utilized in directing prospective research.

Acknowledgements. We thank Auli Immonen for technical assistance and Jari Oksanen for commenting on the manuscript.

\section{References}

Atlas of Finland $1960-38$ pp. Kustannusosakeyhtiö Otava, Helsinki.

Atlas of Finland $1976-30 \mathrm{pp}$. Maanmittaushallituksen karttapaino, Folio 234, Helsinki.

Erkkilä, R. \& Niemelä, T. 1986: Polypores in the parks and forests of the City of Helsinki. - Karstenia 26:1-40.

Eyre, M.D., Foster, G.N. \& Foster, A.P. 1990: Factors affecting the distribution of water beetle species assemblages in drains of eastern England. - J. Appl. Entomol. 109:217-225.

Eyre, M.D. \& Rushton, S.P. 1989: Quantification of conservation criteria using invertebrates. - J. Appl. Ecol. 26:159-171.

Fischer, M. 1987: Biosystematische Untersuchungen an den Porlingsgattungen Phellinus und Inonotus. - Bibl. Mycol. 107:1-133.

Heliövaara, K., Väisänen, R. \& Immonen, A. 1991: Quantitative biogeography of the bark beetles (Coleoptera, Scolytidae) in northem Europe. - Acta Forest. Fennica 219:1-35.

Hill, M.O. 1979a: TWINSPAN - A FORTRAN program for arranging multivariate data in an ordered two-way table by classification of the individuals and attributes. - $48 \mathrm{pp}$. Cornell Univ., Ithaca, NY.

Hill, M.O. 1979b: DECORANA: A FORTRAN program for detrended correspondence analysis and reciprocal averaging. -29 pp. Cornell Univ., Ithaca, NY.

Hill, M.O. \& Gauch, H.G. 1980: Detrended correspondence analysis, an improved ordination technique. - Vegetatio $42: 47-58$.

Kotiranta, H. \& Niemelä, T. 1981: Composition of the polypore communities of four forest areas in southern Central Finland. - Karstenia 21:31-48.

Luff, M.L., Eyre, M.D. \& Rushton, S.P. 1989: Classification and ordination of habitats of ground beetles (Coleoptera, Carabidae) in north-east England. - J. Biogeogr. 16:121-130.

Niemelä, T. 1982: Polypore survey of Finland 1. Introduction. - Karstenia 22:21-26.

Niemelä, T. 1985: On Fennoscandian polypores 9. Gelatoporia n.gen. and Tyromyces canadensis, plus notes on Skeletocutis and Antrodia. - Karstenia 25:21-40.

Niemelä, T. \& Kotiranta, H. 1982: Polypore survey of Finland 2. The genus Phellinus. - Karstenia 22:27-42.

Niemelä, T. \& Kotiranta, H. 1983: Polypore survey of Finland 3. The genera Coltricia, Inonotopsis, Inonotus and Onnia. Karstenia 23:15-25.

Niemelä, T. \& Kotiranta, H. 1986: Polypore survey of Finland 4. Phaeolus, Fistulina, Ganoderma and Ischnoderma. Karstenia 26:57-64.

Niemelä, T. \& Kotiranta, H. 1991: Polypore survey of Finland 5. The genus Polyporus. - Karstenia 31:55-68.

Niemelä, T. \& Saarenoksa, R. 1989: On Fennoscandian polypores 10. Boletopsis leucomelaena and B. grisea described and illustrated. - Karstenia 29:12-28.

Peet, R.K. 1978: Latitudinal variation in southern Rocky Mountain forests. - J. Biogeogr. 5:275-289.

Renvall, P., Renvall, T. \& Niemelä, T. 1991: Basidiomycetes at the timberline in Lapland 1. Introduction. - Karstenia 31:1-12.

Ter Braak, C.J.F. 1985: Correspondence analysis of incidence and abundance data: properties in terms of a unimodal response model. - Biometrics 41:859-873.

Ter Braak, C.J.F. 1986: Canonical correspondence analysis: A new eigenvector technique for multivariate direct gradient analysis. - Ecology 67:1167-1179.

Ter Braak, C.J.F. 1987: CANOCO - a FORTRAN program for canonical community ordination by [partial] [detrended] [canonical] correspondence analysis, principal components analysis and redundancy analysis (version 2.1). - $95 \mathrm{pp.}$ TNO Institute of Applied Computer Science, Wageningen.

Tuhkanen, S. 1980: Climatic parameters and indices in plant geography. - Acta Phytogeogr. Suecica 67:1-110.

Väisänen, R., Heliövaara, K. \& Immonen, A. (in press): Biogeography of northern European insects: provincial data in gradient analyses (Saltatoria; Lepidoptera: Sesiidae; Coleoptera: Buprestidae, Cerambycidae). - Ann. Zool. Fennici.

Received on 13 June 1991 